\title{
Measuring the socio-economic footprint of the energy transition
}

\author{
Xavier Garcia-Casals ${ }^{1} \cdot$ Rabia Ferroukhi $^{1} \cdot$ Bishal Parajuli ${ }^{1}$
}

Received: 27 April 2019 / Accepted: 30 September 2019 / Published online: 24 October 2019

(c) The Author(s) 2019

\begin{abstract}
The energy system is often treated as a self-contained system, disconnected from the broader socio-economic structures it is built upon. Understanding the enabling environment and structural elements will help to maximize the benefits of the transition and increase awareness of potential barriers and necessary adjustments along the way. IRENA has developed a methodology to measure the socio-economic footprint of energy transition roadmaps using the E3ME macro-econometric model, which evaluates the likely impacts in terms of gross domestic product (GDP), employment and human welfare. It is based on well-established historical databases and has a proven track record of policy applications. The presented socioeconomic footprint analysis is based on the IRENA REmap energy transition roadmap 2018 that explores a higher deployment of low-carbon technologies, mostly renewable energy and energy efficiency. The results show that, with appropriate policies in place, reducing over $90 \%$ of the energy-related carbon dioxide emissions from the reference case via renewables and energy efficiency coupled with deep electrification of end-uses, results in consistently positive global GDP impacts across the period of analysis from 2018 to 2050 . Across the world economy, the transition case leads to a relative increase of employment by $0.14 \%$ over the reference case throughout the analysed period from 2018 to 2050. In addition to GDP and employment growth, the energy transition can offer broader welfare gains. However, not all countries and regions around the world benefit equally, and just transition policies must be included to ensure all regions and communities are able to take advantage of the energy transition.
\end{abstract}

Keywords Energy transition $\cdot$ Renewable energy $\cdot$ Socio-economic footprint $\cdot$ Macroeconomic impacts $\cdot$ Jobs

\section{Introduction}

Addressing the climate challenge requires transforming the current carbon-intensive energy system into a decarbonized one. Models are used to explore the feasibility of this transformation and outline transition pathways. The models that have been used to produce transition scenarios can be classified in three main categories: energy system models (EMs), energy-economy models (EEMs) and integrated ${ }_{1}^{1}$ assessment models (IAMs). The difference between these categories are the number of systems included (increasing from EMs to EEMs and IAMs) and the level of detail at which the energy system is treated ${ }^{2}$ (decreasing from EMs to EEMs and IAMs). The trade-offs between simplifying the

The authors are at the International Renewable Energy Agency, but the views expressed in this paper are those of the authors and do not necessarily represent those of the Agency.

Rabia Ferroukhi

rferroukhi@irena.org

1 International Renewable Energy Agency, Abu Dhabi, UAE energy system modelling approach and including more systems have important consequences on the resulting energy transition scenarios, with most EEMs and IAMs having been up until now unable to properly capture the full potential of transitioning to a RE-based energy system. Another important limitation of most EEMs and IAMs is their reliance on cost optimization formulations, which when applied with highly uncertain and often biased inputs, assumptions and formulations, produce transition scenarios that can significantly distort the options to address the transition.

\footnotetext{
${ }_{1}^{1}$ From Cambridge Econometrics.

${ }^{2}$ It should be noted that from the different systems involved in the transition (energy, economy, social, climate), the energy system is by far the simplest. The modelling simplifications introduced in the energy system have a significant impact on the resulting transition pathways as discussed in this paper. Hence, similar impacts could be expected from the simplifications introduced in the economy, social and climate systems.
} 
EMs have been used to explore the feasibility of transitioning towards renewable energy (RE)-based energy systems, and to explore the full potential of renewables, energy efficiency and energy flexibility, which are often untapped in EEMs and IAMs due to simplifications they introduce in the treatment of the energy system. The scenarios produced with EMs also include links to and insights from the socioeconomic and environmental systems. It should be noted that these are either input assumptions (i.e. GDP and population scenarios) or ex-post-evaluations [i.e. costs, jobs, pollution, greenhouse gas (GHG) emissions], but not dynamic systemic couplings. The detailed, often bottom-up energy system model formulation approach from EM has allowed exploring the feasibility and techno-economic implications of transitioning towards RE-based energy systems.

An early detailed evaluation of the techno-economic feasibility of $100 \%$ RE-based power systems at national scale was provided by Greenpeace Spain in Ref. [1], while in Ref. [2] presents $100 \%$ RE-based whole energy system integrated scenarios at national scale, including a detailed bottom-up evaluation of the potentials from energy efficiency and flexibility. Greenpeace International provides a high RE transition scenario for the world in Ref. [3]. More recent EM scenarios like [4] and [5] provide pathways for $100 \%$ RE-based whole energy system at global scale, and others directly focus on the feasibility to achieve the $1.5^{\circ} \mathrm{C}$ global warming goal from the Paris Agreement and the role that the transition from the energy system to $100 \% \mathrm{RE}$ has on it. Some of these EMs [6] include cost-optimization routines, while others [7] directly acknowledge the limitation of cost-optimized pathways due to input uncertainties and instead focus on multi-criteria decisions to inform the transition pathway.

EEMs include both the energy and economy systems into the modelling framework. However, the scope of how these two systems are considered is often limited. The energy system is considered with less detail than in EMs, which often has prevented capturing the full transition potential of renewables, energy efficiency and energy flexibility in these scenarios. This trend has often been reinforced by inappropriate exogenous modelling assumptions about costs and performance from transition technologies. Regarding the economic system, most EEMs limit it to the economy of the energy sector with few exogenous links with global macroeconomic variables, and they do not internalize the economic and social impact of externalities. EEMs are often based on cost optimization routines, which given their limitations in the modelling of both the energy and economy systems, produce transition pathways with a strong bias towards conventional technologies.

The World Energy Outlook (WEO) from the IEA ${ }^{3}$ [8] based on the World Energy Model [9] is one example of

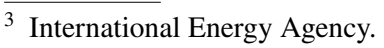

EEM that has been used over the past decades [10] to provide yearly updates of energy system scenarios. These scenarios have been significantly influencing energy policy and business decisions. Their limitations to capture the technoeconomic performance of transition technologies (renewables, efficiency and flexibility), with yearly updates on WEO's projections often lagging contemporaneous reality, has led to boost fossil fuel investments (as the IEA itself recognized in 2019 [11]), which will now have to be stranded, implying huge impacts on the socio-economic system that were not factored into the cost optimization routines that produced these scenarios. ${ }^{4}$

IAMs have been developed with the focus on analysing climate change and its mitigation. The fifth assessment report from the IPCC ${ }^{5}$ [12] provided a compilation of IAMbased scenarios as of 2014. The core from IAMs are carbon cycle and climate models, but its integrated approach attempts to capture feedbacks between the different systems, and hence they include energy and economy models within their scope. However, both the energy and economy system model formulation within IAMs have significant simplifications, which together with the cost-optimization routines from IAMs lead to transition scenarios that often miss the potential from transition technologies. Another consequence of the simplified energy and economy system formulations of IAMs is the limitation on accepted policy inputs, in such a way that IAMs often default to an approach of deriving techno-economic optimal technology deployment subject to an input of carbon price. These limitations have become most evident when applying IAMs to search and analyse mitigation pathways consistent with the $1.5^{\circ} \mathrm{C}$ global warming climate goal from the Paris Agreement [13-16]. The most recent IPCC Special Report on $1.5^{\circ} \mathrm{C}$ [17] compiling the available IAM-based scenarios consistent with the $1.5^{\circ} \mathrm{C}$ climate goal acknowledges that the potential from transition technologies as evaluated by detailed EMs is still not fully captured into IAM-based cost-optimal transition pathways.

EMs, EEMs and IAMs have provided useful insights for the energy transition, from the EM's detailed feasibility analysis of RE-based energy systems to some of the main

\footnotetext{
${ }^{4}$ There are important lessons to be learned from the dysfunctional impact of these scenarios for the socio-economic system. If scenarios are to support planning and policy-making for a successful transition, they should focus on the fast and sustainable deployment of available transition technologies (renewables, efficiency, flexibility) and the required restructuration of the power, energy and socio-economic systems. Scenarios that incentive further deployment of FF-era technologies, attempt to perpetuate the structures that produced the current climate crisis, or that rely on technologies (ie nuclear or CCS) that are unproven or that lack the capability to fulfil the transition's sustainability and reliability requirements and be applied for the whole world within the available transition's time window, will ultimately act as additional transition barriers and increase the burden to society.

5 Intergovernmental Panel on Climate Change.
} 
Fig. 1 Power and energy systems as a part of a broader system. Source: [24]
Fig. 2 The energy transition and its socio-economic footprint. Source: [23]
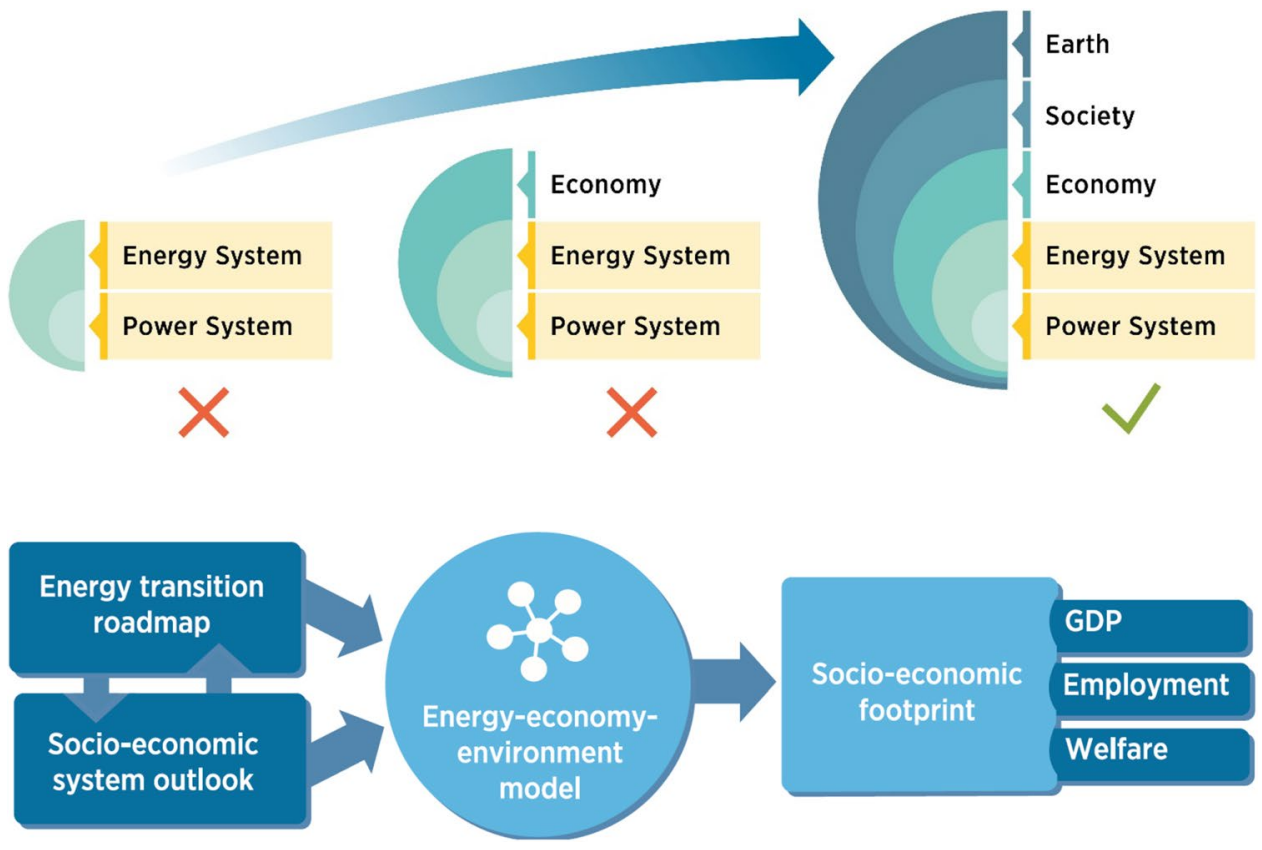

inter-systemic feedbacks captured by IAMs. These models have produced a huge diversity of energy transition pathways, from the more trending ones produced by the cost optimization routines of EEMs and IAMs missing the disruptive capabilities of transition technologies to full $100 \%$ RE scenarios produced by detailed EMs. With different degrees of success, these insights have been used for setting the agenda of the transition, but there is now an urgent need to move towards the impact assessment of transition pathways. Indeed, scenarios only exist on paper-as we move towards the deployment phase, appropriate policymaking and transition planning require further insights on the systemic impacts of deploying any of these scenarios. In that, the structure and modelling approach of most current EMs, EEMs and IAMs are not appropriate. The macroeconometric model E3ME has already been used to shift the modelling approach away from the agenda-setting towards the impact assessment mode in Refs. [18-20].

The socio-economic footprint analysis from IRENA ${ }^{6}$ [21-24] aims at generalizing this evolution towards the impact assessment mode by providing a methodology that can fill the knowledge gaps of overall systemic impacts from any energy transition roadmap. The analysis provides insights on the likely overall systemic consequences of implementing any specific energy transition roadmap. This

\footnotetext{
6 The International Renewable Energy Agency (IRENA) is an intergovernmental organization that supports countries in their transition to a sustainable energy future, and serves as the principal platform for international cooperation, a centre of excellence, and a repository of policy, technology, resource and financial knowledge on renewable energy.
}

can then inform policy-making and transition planning to maximize synergies and prevent transition barriers.

The energy system is embedded into the wider economy, which in turn is embedded into the social system, and the Earth system (Fig. 1). Standalone energy or energy-economy transitions do not exist. And the reality of the systems out there is far more complex than some of its first layers as captured in EEMs and IAMs, with many feedbacks between systems leading to the final outcome [24-26]. Capturing the complexity of the real economic and social systems in the modelling setup is of paramount relevance for a proper impact assessment of the implementation of energy transition roadmaps [18]. This is because the changes in the energy system required to address the climate challenge have impacts throughout the economy and society that are dependent on this complexity. ${ }^{7}$ They trigger a set of challenges and opportunities. Understanding the enabling environment and structural elements will help to maximize the benefits and increase awareness of potential barriers and necessary adjustments along the way.

When trying to implement any energy transition roadmap, it will interact with the evolution of the socio-economic system upon which it is deployed, producing a series

\footnotetext{
7 This is why a non-equilibrium econometric modelling approach is used for the socio-economic footprint analysis instead of a general equilibrium model, as well as a model with high geographical and sectoral granularity, in such a way that the effect from the different macroeconomic interactions between regions and sectors can be captured.
} 
of outcomes that can be understood as its socio-economic footprint. IRENA has developed a methodology to measure the socio-economic footprint of any energy transition roadmap (see Fig. 2). The integrated modelling approach and the detail and granularity of the models used allow evaluating the net effect from the multiple interactions between the energy and the socio-economic system, overcoming, therefore, the simplification of ex-post socio-economic evaluations from other transition analyses. An integrated econometric-energy model evaluates the likely impacts in terms of gross domestic product (GDP), employment and human welfare. It analyses the drivers and dynamics affecting the outcome to provide valuable insights into how the overall transition process can be shaped to maximize benefits and overcome barriers. Based on its 2018 REmap energy transition roadmap, ${ }^{8,9}$ IRENA has applied this methodology to evaluate and obtain insights into the socio-economic footprint of the transition process to 2050. The macroeconomic model used for this analysis $\left(\mathrm{E} 3 \mathrm{ME}^{10}\right)$ and some of its key inputs are discussed in "Methodology", followed by an analysis of key results in "Results", and a conclusion in "Conclusions".

\section{Methodology}

The socio-economic footprint of the energy transition presented in this study is obtained using the E3ME macro-econometric model, ${ }^{11}$ developed by Cambridge Econometrics, which is based on well-established

\footnotetext{
${ }^{8}$ REmap is IRENA's energy transition roadmap up to 2050. The REmap roadmap and its socio-economic footprint are regularly updated [21-24]. The results herewith presented correspond to the 2018 REmap [23].

9 The socio-economic footprint analysis from the REmap energy transition roadmap has been carried out using the E3ME econometric model from Cambridge Econometrics. The time resolution of the socio-economic footprint analysis is 1 year, from today up to 2050 .

$10 \mathrm{E} 3 \mathrm{ME}$ is a macro-econometric model developed and maintained by Cambridge Econometrics. The full manual for the model is available at the model website http://www.e3me.com/.

11 The E3ME macro-econometric model represents aggregate human behaviour through a chosen set of econometric relationships that are regressed on the past 45 years of data and are projected into the future. The model has high geographical and sectoral granularity. The whole world is included in the model, through more than 60 countries, regions and country groupings. For each one of these, the sectoral resolution of the economy includes about 70 economic sectors. The regions/countries are linked through bilateral trade equations, while input-output tables provide the linkages between the different sectors.

12 As a macro-econometric model, E3ME's data requirements are extensive, with time-series data required for each indicator in each sector in each country. The current model database covers since 1970 and the main data sources are Eurostat, OECD, World Bank, IMF, IEA and national statistical agencies.
}

historical databases ${ }^{12}$ and has a proven track record of policy applications. ${ }^{13}$

The E3ME model comprises [37]:

- a comprehensive accounting framework of the world economy, disaggregated by countries and regions, coupled with balances for energy and material demands and environmental emission flows;

- detailed historical data sets since 1970, and sectoral disaggregation;

- an econometric specification of behavioural relationships. ${ }^{14}$

Figure 3 shows the interactions between the three components (modules) of the model (energy, environment and economy). Although the E3ME model can endogenously evaluate the evolution of the energy system as a response to policy inputs, for evaluating the socio-economic footprint from a given energy transition roadmap, the energy balances used in this analysis are introduced exogenously. Exogenous elements introduced to analyse the REmap roadmap ${ }^{15}$ are shown on the left and right sides of Fig. 3 and are detailed in Table 1. For the economic system, they are investment costs, fossil fuel subsidies and carbon taxes, each of them with its time dependency. For the energy system, they are the detailed energy balances and its time dependency. ${ }^{16}$ The socio-economic footprint of both transition and the reference cases are measured, and the results are presented for transition relative to the reference case.

- The reference case ${ }^{17}$ is a scenario that takes into account the current and planned policies of countries. It includes commitments made in the NDCs and other targets,

${ }^{13}$ E3ME had been successfully applied previously by Cambridge Econometrics to assess energy and climate policies for institutions such as the European Commission [27], the Irish and UK Governments [28], Renewable UK [29]. Other examples of recent applications of E3ME include: [18-20, 30-36].

14 The E3ME macro-econometric model has country level and sectorial resolution and uses a timestep of one year.

15 The REmap roadmap includes two scenarios: The reference case and the transition case.

${ }^{16}$ More details on the REmap roadmap are available at https://www. irena.org/remap. A complete list of differences, including details on energy mixes and investments is available at Ref. [23].

${ }^{17}$ In the reference case, the energy-related $\mathrm{CO}_{2}$ emissions by 2050 are $34.8 \mathrm{GtCO}_{2}$ /year adding up to $1230 \mathrm{GtCO}_{2}$ in cumulative terms since 2015. By 2050 the share of renewables in total final energy consumption is $24 \%$, the share of renewables in power generation is $47 \%$ and the total electrification rate $27 \%$ The cumulative investment in the energy sector from 2015 to 2050 amounts to 93 2015USD trillion. 


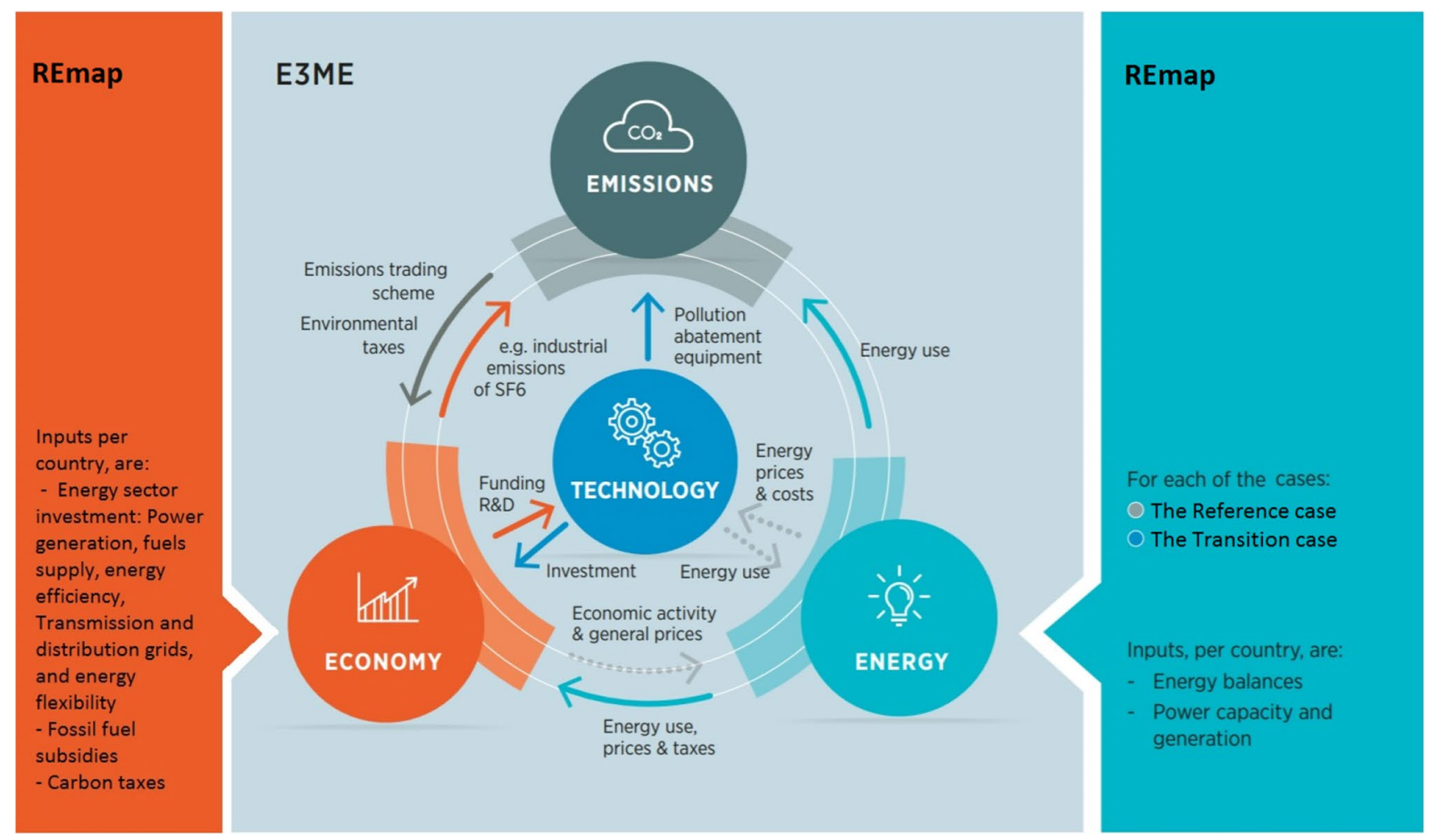

Fig. 3 Energy, economy and environment in the E3ME model

reflecting governments' current projections and energy plans.

- The transition case ${ }^{18}$ is a transition scenario that explores a higher deployment of low-carbon technologies, mostly renewable energy and energy efficiency, based on a dialogue between IRENA and its Member States.

Unlike most of the economy system modelling in EEMs and IAMs, which implement general equilibrium models and cost-optimization routines, ${ }^{19}$ the E3ME econometric model

\footnotetext{
18 In the transition case, the energy-related $\mathrm{CO}_{2}$ emissions by 2050 are $9.7 \mathrm{GtCO}_{2}$ /year adding up to $760 \mathrm{GtCO}_{2}$ in cumulative terms since 2015. By 2050 the share of renewables in Total Final Energy Consumption is $62 \%$, the share of renewables in power generation is $84 \%$ and the total electrification rate $45 \%$ The cumulative investment in the energy sector from 2015 to 2050 amounts to 120 2015USD trillion.

19 Rendering them unsuitable to assess the socio-economic impacts of realistic baskets of climate and energy policies [[18], [19]]. As pointed out above, the limitations on assumptions and implemented modelling detail often drive cost-optimized scenarios away from the transition potential. Moreover, as noted in Ref. [38], it only requires one agent to make suboptimal decisions for the system of optimization to break down as a whole, and in the real economic system there are many agents making suboptimal decisions.
}

is based on non-equilibrium economics where the dynamical (time-dependent) aggregated human behaviour is driven by empirically determined dynamic relationships, with full coupling between the different sectors of the economy (including the energy sector) and economies of the world. Under this more realistic and detailed model formulation, with different policies interacting with one another, a significantly wider policy space becomes available to provide insights for effective transition policy-making.

The assumptions about the evolution of the underlying socio-economic system also impact the socio-economic footprint. For the 2018 REmap roadmap analysis herewith presented, a trending evolution of the current socio-economic system as described by the E3ME econometric formulation ${ }^{20}$ is assumed. The scenarios are run until the year 2050 with yearly resolution.

The required exogenous inputs depend on the kind of socio-economic footprint analyses to be undertaken and may

\footnotetext{
${ }^{20}$ In terms of the shared socio-economic pathways (SSPs) [39-41] the E3ME baseline socio-economic outlook is similar to SSP2 (middle of the road SSP) in terms of population, to SSP5 (fossil-fueled development SSP) in terms of absolute GDP and to SSP1 (sustainable development SSP) in terms of per capita GDP.
} 


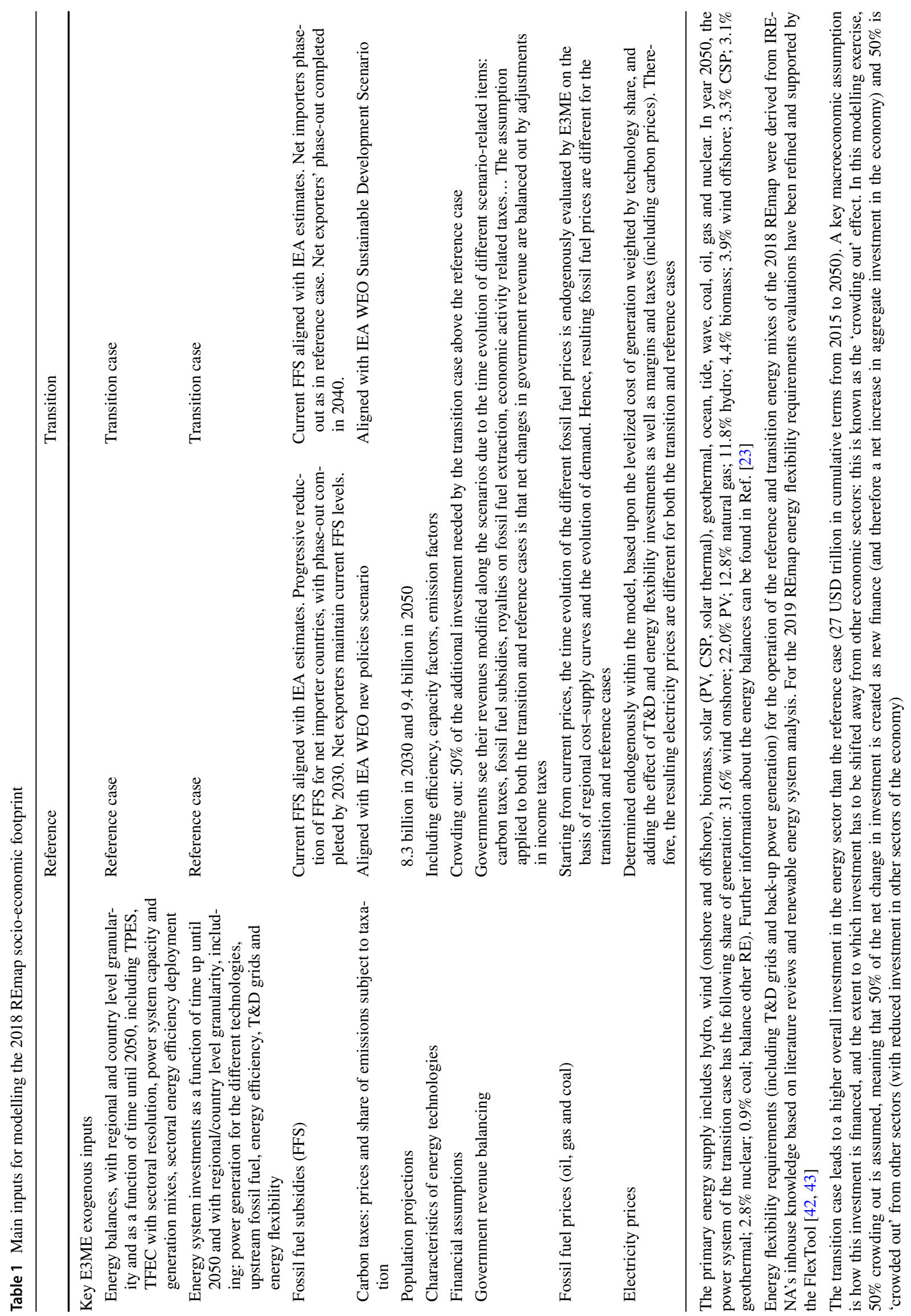


Table 2 Details of indicator and sub-indicators to compute the welfare index Source: [26]

\begin{tabular}{|c|c|c|c|c|}
\hline Dimension & Sub-indicator & $\begin{array}{l}\text { Detail (all data are given in each year of the energy } \\
\text { transition period and each country) }\end{array}$ & Units & $\begin{array}{l}\text { Weight in the } \\
\text { aggregated } \\
\text { indicator }\end{array}$ \\
\hline \multirow[t]{2}{*}{ Economic } & Consumption plus investment & $\begin{array}{l}\text { Sum of household consumption and economy-wide } \\
\text { investment (i.e. capital formation) }\end{array}$ & Constant 2015 US \$ & $1 / 6$ \\
\hline & Employment & $\begin{array}{l}\text { Economy-wide employment in all }<70>\text { economic sec- } \\
\text { tors considered }\end{array}$ & Number of jobs & $1 / 6$ \\
\hline \multirow[t]{2}{*}{ Social } & Spending on education & Public and private spending in education & Constant 2015 US \$ & $1 / 6$ \\
\hline & Health impacts & $\begin{array}{l}<\text { Energy consumption in power generation and end-use } \\
\text { sectors (TJ) differentiated by fuel and multiplied by } \\
\text { health externality }(\$ / T J) \text { for each fuel from IRENA } \\
\text { analysis }>\end{array}$ & Constant 2015 US \$ & $1 / 6$ \\
\hline \multirow[t]{2}{*}{ Environmental } & GHG emissions & $\begin{array}{l}\text { Cumulative GHG emissions (using the global value for } \\
\text { the indicator in all countries) } \\
\text { Cumulative values are used because these are the } \\
\text { ones that relate to the associated externality (climate } \\
\text { change) }\end{array}$ & t CO2 eq. & $1 / 6$ \\
\hline & Material consumption & $\begin{array}{l}\text { Cumulative use of materials excluding fossil fuels } \\
\text { Cumulative values are used because these are the ones } \\
\text { that relate to the associated externality in most cases } \\
\text { (depletion of finite resources) }\end{array}$ & Gt & $1 / 6$ \\
\hline
\end{tabular}

Increases in some of these indicators have a positive contribution to welfare (consumption plus investment, employment, spending on education), while others have a negative contribution (health impacts, GHG emissions, material consumption)

E3ME includes a high disaggregation of the economy in its different economic sectors and activities, as well as the interactions among these. These sectors include energy-related ones (coal, oil and gas, electricity, air transport, water transport, coke and refined petroleum, mining...), industrial (electric equipment, fabricated metal products, rubber and plastic products, paper, chemicals, pharmaceuticals, motor vehicles, computer, optical, electronic...), services (computer programming, legal, accounting, consulting, retail, accommodation, real state, education, health...) and other (crops, forestry, fishing, textiles...). Further details can be found in the full manual for the model available at the model website http://www.e3me.com/

change as different socio-economic aspects are addressed. Table 1 describes some of the inputs used for the analysis of the 2018 REmap socio-economic footprint [23].

The human welfare indicator presented in this analysis incorporates the widely accepted three dimensions of sustainable development: economic, social and environmental [26]. The economic dimension is measured in terms of total employment and through consumption plus investment (which considers current expenditure plus the future benefits from an improved capital stock). The social dimension includes total (public and private) expenditure in education and health improvements from reduced air pollution. The environmental dimension is captured through reductions in GHG emissions and natural resource depletion (measured in terms of direct material consumption-DMC — of minerals and biomass for food and feed, excluding fossil fuel energy resources). Since each sub-indicator is expressed in different units (as shown in Table 2), all six sub-indicators are measured as the relative difference between the transition and reference cases, then weighted equally and aggregated into the overall indicator.

\section{Results}

The close interplay between the energy sector and the economy generates several impacts in terms of GDP, employment and human welfare, namely the socio-economic footprint.

While global results are positive for GDP and employment, there are significant divergences on the regional level. For the welfare indicator, global and regional outcomes are positive.

\section{Global GDP}

With appropriate policies in place, reducing over $90 \%$ of the 2050 energy-related carbon dioxide emission via renewables and energy efficiency results in consistently positive global GDP impacts across the period of analysis from 2018 to 2050 . Compared to the reference case, the gain under the transition case peaks at $1.5 \%$ of GDP in 2031, and then gradually narrows to $1.0 \%$ in 2050 . 


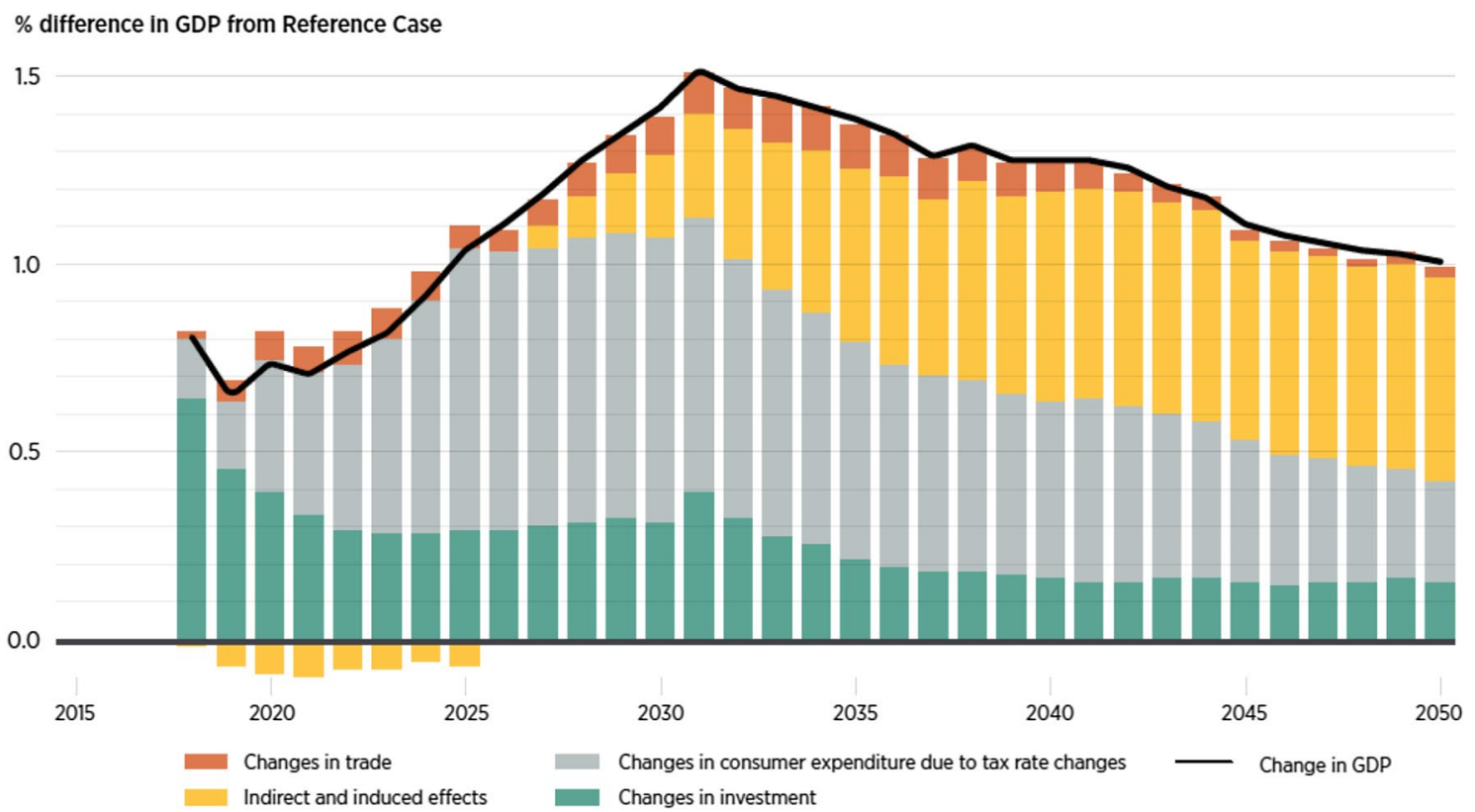

Fig. 4 Relative difference of global GDP between the transition case and the reference case

Figure 4 quantifies the expected contributions to the GDP of four key drivers-investment, ${ }^{21}$ trade, ${ }^{22}$ tax changes, ${ }^{23}$ and indirect and induced effects. ${ }^{24}$ In the short- to mid-term (until 2035) a front-loaded investment stimulus (spending on energy efficiency, energy flexibility and power sector) dominates the outcome along with changes in consumer expenditures triggered by tax and subsidy changes. In the post-2035 period these drivers fade in importance. Instead, indirect and induced effects play the most significant role in

\footnotetext{
${ }^{21}$ Investment-overall energy sector investment. For the transition case it is dominated by the investment required for the energy transition (power generation, transmission and distribution, energy flexibility and energy efficiency). The reference case has higher fossil fuel investments.

22 Trade-the impact of changes in imports and exports on GDP. An increase in imports, or reduction in exports, has a negative impact on GDP, while a decrease in imports or increase in exports has the reverse effect. Trade effects are almost neutral at global level because of the nature of trade but have important impacts at regional level.

23 Tax rate-due to the revenue balancing assumption income taxes change and impact economic activity. A change in government tax take (whether via the carbon taxes, fossil fuel subsidies, economic activity or a reduction in tax associated with fossil fuel production) is compensated by a change in income taxes (up if there is an overall decrease in government revenues, and down is there is an increase).

${ }^{24}$ Indirect and induced effects-this captures all other changes in consumer expenditure. The indirect effect refers to the additional boost to GDP which can arise through payments to producers in the supply chain. Induced effects are similar in nature to indirect effects but arise from payments to workers rather than payments to other producers in the supply chain.
}

the second half of the transition period. This reflects reduced expenditure on energy (mainly fossil fuels) and reallocation of this spending to other parts of the economy. The presence of diversified, deep and long supply chains translates into increased indirect effects, and increased demand for jobs and wages (and subsequent changes in net household incomes) lead to induced effects: As more household expenditure is reallocated from energy to other goods and services, GDP benefits increase accordingly. Trade impacts balance out on the global level but are more visible on the regional or national level.

\section{Regional GDP}

As is the case with any economic transition, some regions and countries will fare better than others due to diverging structures, capacities and dynamics. Figure 5 illustrates that Western Europe and most G20 countries, for example, experience GDP gains due to diversified economies, strong domestic supply chains, favourable trade balances and limited dependence on fossil fuel exports. On the other hand, economies dependent on the sale of fossil fuels-such as the Russian Federation, African members of the Organization of the Petroleum Exporting Countries (OPEC) and other net oil exporters-confront negative impacts due to forgone investment and lower export revenues, non-diversified economies and weaker domestic supply chains for transition-related equipment and services, with its associated smaller indirect and induced effects. Among the "Rest of Africa" group are high-cost fossil fuel exporters that are very sensitive to the 


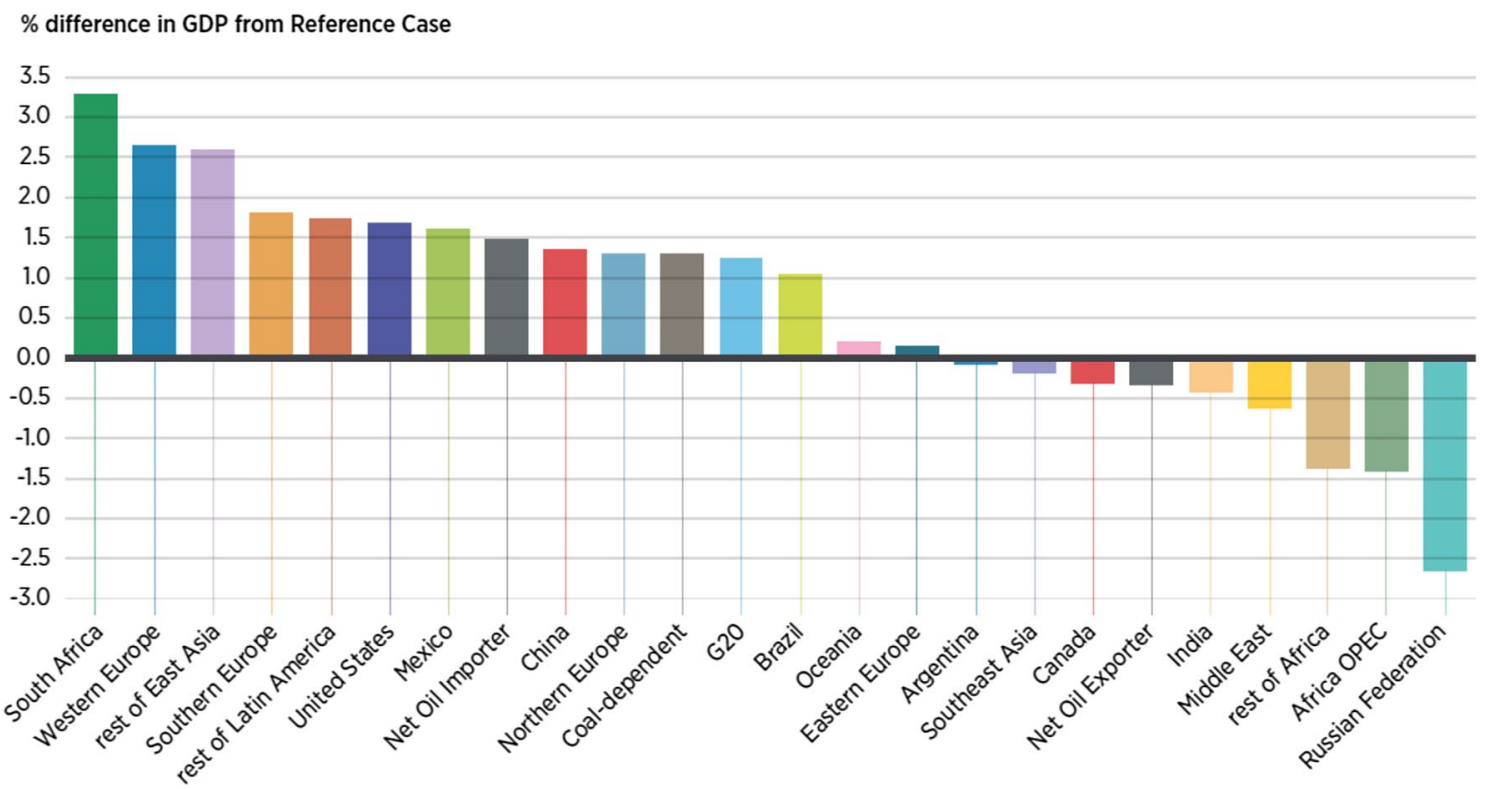

Fig. 5 Difference in regional and national GDP from reference case in the year 2050

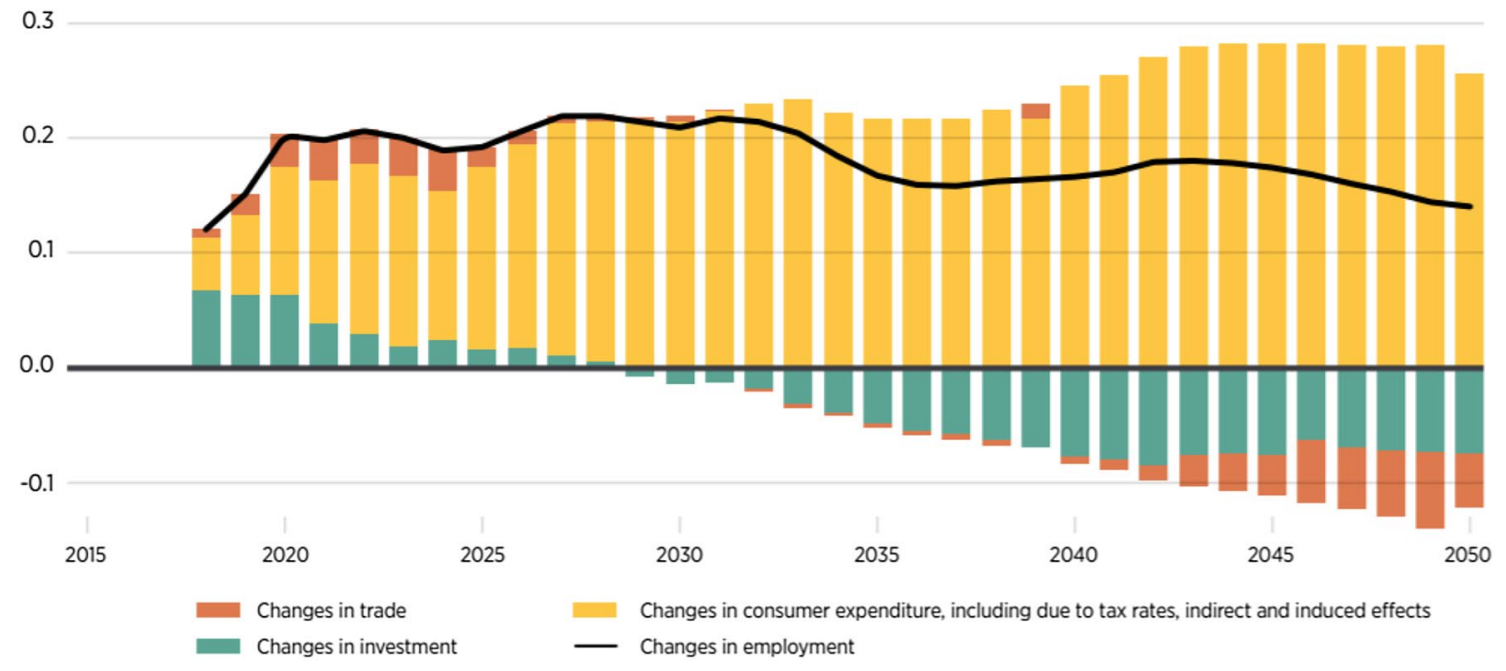

Fig. 6 Relative difference in employment in percentage, compared to the reference case

reduction in global fossil fuel demand. Meanwhile, they are unable to take full advantage of the new economic opportunities due to weak domestic supply chains and an increasing reliance on imports.

\section{Global employment}

Across the world economy, the transition case leads to a relative increase in employment over the reference case throughout the analysed period from 2018 to 2050 (Fig. 6). From the analysis of the drivers of the relative increase in employment it can be concluded that the increase is mostly due to changes in consumer expenditure. In the short term, this effect is driven by tax rate changes, while the indirect and induced effects become more important in the longer term.

Compared to added GDP growth of $1 \%$ in 2050, employment for the economy as a whole gains $0.14 \%$ under the transition case are relatively limited. This is because the expected growth in wage volume resulting from additional demand in the economy can either be realized as wage increases for all workers or as increases in the total number of jobs-or as a mixture of both effects. Historical trends indicate that the wage effects tend to dominate. 


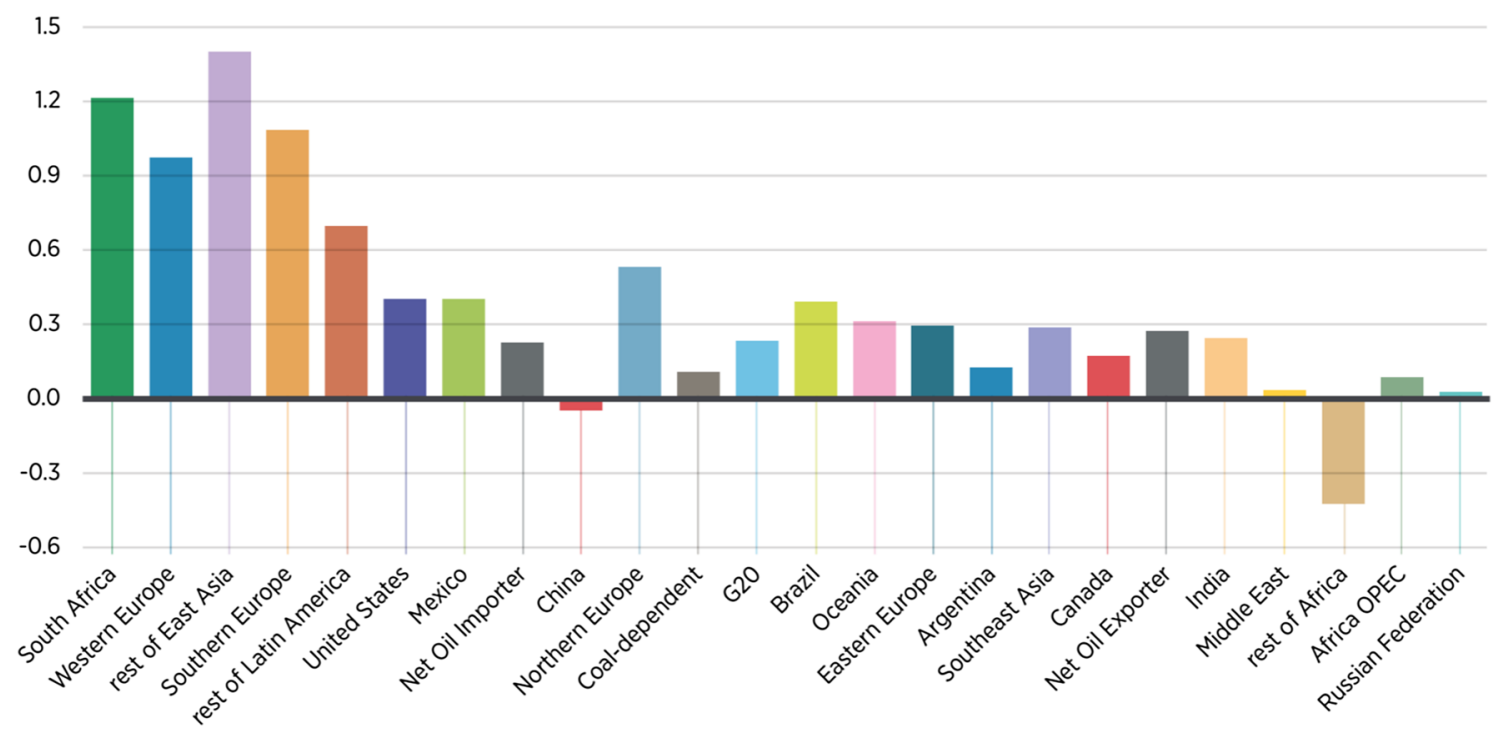

Fig. 7 Difference in regional employment compared to reference case in the year 2050

\section{Regional employment}

Figure 7 presents transition case employment outcomes in 2050 relative to the reference case in different regions, countries and groups of countries. Although net job gains fluctuate over time, almost all regions and countries enjoy a positive employment impact from the transition, despite many of them losing many jobs in the fossil fuel sector as fossil fuel demand declines. By 2050, only the Rest of Africa fares significantly worse than in the reference case, while China shows a slight underperformance due to loss of jobs in coal sector. The negative impact faced by developing countries (mostly in Africa and possibly to some extent in parts of Asia) suggests that within the current socio-economic structure, the transition does not bring about fair and socially just results. Improving the negative social impacts will require changing the existing economic structures that produce such outcomes.

\section{Global welfare}

In addition to GDP and employment growth, the energy transition can offer broader socio-economic benefits. Most importantly, all countries and regions see significant health and environmental benefits from the transition, even those where GDP and employment results are less desirable.

Figure 8 shows that the transition case offers significant global welfare gains relative to the reference case and indicates the contribution of the six welfare sub-indicators ${ }^{25}$ :

\footnotetext{
25 As already indicated above, equal weightings are used for each of the six welfare sub-indicators. Different transition stakeholders could however give higher value to some sub-indicators over the other ones, which would lead to a different overall welfare indicator value. Since
}

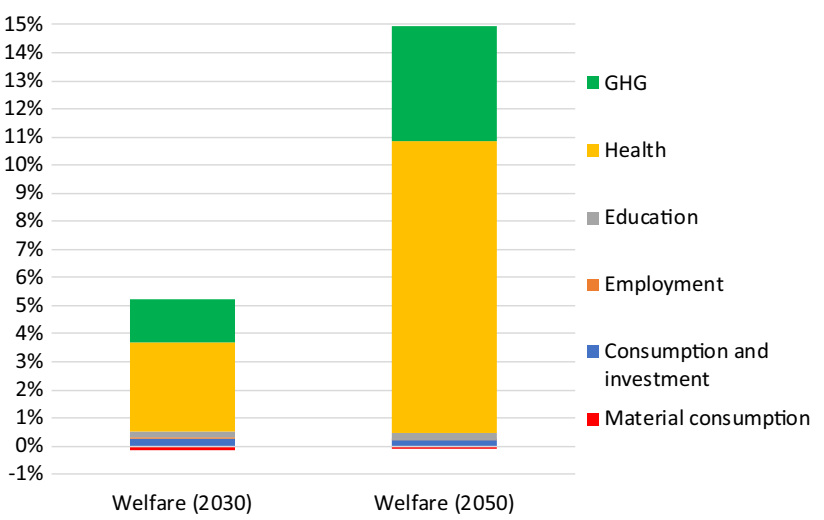

Fig. 8 Transition welfare indicator components in 2030 and 2050

reductions in GHG emissions, health improvements, spending on education, employment, consumption and investment, and material consumption. It should be noted that two subindicators dominate the impact of the overall welfare indicator, namely the reduction in negative health effects from local air pollution (62\% improvement in 2050$)$ in the social dimension and the reduction in greenhouse gas emissions (25\% improvement in 2050) in the environmental dimension.

\section{Footnote 25 (continued)}

equal weightings are used (1/6) for each of the welfare dimensions, the reported results showing the contribution from each sub-indicator can be used by the reader to generate other welfare aggregates with different weightings for each sub-indicator. This and transparency in welfare reporting have been the main drivers to choose equal weightings for the different welfare dimensions in the presented results. It is outside the scope of this paper to discuss what the appropriate weightings could be for different stakeholders. 
The welfare indicator improves as the transition progresses, going from around $5 \%$ by 2030 to around $15 \%$ in 2050 as the health and environmental benefits are reaped.

Most importantly, all countries and regions see significant health and environmental benefits from the transition, even those where GDP and employment results are less desirable.

\section{Conclusions}

The interactions between the energy sector and the broader socio-economic system determine the outcomes of the energy transition with regard to GDP, employment and overall human welfare. A holistic transition approach seeks to maximize synergies while avoiding or minimizing the potential barriers.

The analysis of the socio-economic footprint from the REmap energy transition roadmap shows positive results in terms of GDP, employment and welfare at global level, with the welfare benefits going well beyond GDP improvements and being strongly dominated by social and environmental benefits (reduction of local air pollution and reduced climate impacts due to reduced $\mathrm{GHG}$ emissions).

This positive global socio-economic impact from the transition, and specifically its positive impact on GDP and employment, is aligned with the results from other transition analyses [31, 44-50] and resonates with the underlying arguments of 'green growth' proponents [51-54], reinforcing the aim of the UN SDG8. ${ }^{26}$ This positive socio-economic impact is also one of the main drivers from the Green New Deal [55, 56]. However, the very dependence on growth of the current economic system, at least when applied indiscriminately to all regions regardless of their current GDP, and with it all the green growth initiatives, are being intensely challenged on the grounds of finite resources and some of its detrimental dynamics [57-59].

Despite the positive global socio-economic impacts, results illustrate that not all countries and regions around the world benefit equally from the REmap energy transition; and some actually experience reductions of GDP or employment relative to the reference case. Indeed, regional results show significantly different socio-economic footprints, with clear winners and losers, and increasing inequalities that could eventually develop as transition barriers. This means that depending on context, specific energy, economic and social policies will be needed to ensure that benefits from the energy transition accrue to all.

Different outcomes of the transition on countries and regions result from several factors, beginning with diverging

\footnotetext{
${ }^{26}$ United Nations Sustainable Development Goal 8: Decent Work and Economic Growth (https://sustainabledevelopment.un.org/sdg8).
}

levels of transition ambition among countries. Outcomes also relate strongly to underlying structural realities and the degree to which governments undertake certain actions such as diversifying the economy away from fossil fuels, implementing carbon tax systems, phasing out fossil fuels and reinforcing transition-related domestic supply chains in an effort to guide their economies toward a low-carbon future.

The ability of a given country to reap GDP, employment and human welfare benefits depends to a large extent on the degree to which domestic supply chains can respond to new demand patterns stimulated by the transition. Countries with well-developed industries and service sectors, such as in Western Europe or China, will benefit significantly. But countries that depend heavily on imported inputs will need to adopt policies to strengthen and deepen their domestic supply chains.

Further, economies that strongly depend on fossil fuel exports will face considerable challenges during the transition, especially if adjustment efforts are limited or undertaken with delay. Our analysis finds that oil exporters in the Middle East, parts of Africa, and the Russian Federation will have lower GDP and employment growth in the energy transition (transition case) than under the reference scenario.

Less favourable transition socio-economic footprints in low-income countries must be addressed for the transition to be successful. Increasing the energy transition ambition and prioritizing climate finance to steer the transition in these countries, reinforcing domestic supply chains to reap indirect and induced effects from the transition, implementing fair trade relationships that provide the economic space for the different countries to reap and share the transition benefits, and redirecting global economic flows with fairness criteria (i.e. regional redistribution of carbon tax incomes), can all contribute to address these issues.

Overall, the energy transition will generate more jobs in renewable energy and energy efficiency than will be lost in the fossil fuel sector. ${ }^{27}$ However, the geographic

\footnotetext{
27 Under conventional neoclassical and neoliberal economic thinking, the fact that the transition requires a higher number of energy sector jobs per unit of energy used by the economy could be understood as a negative impact from the transition: a decrease of employment productivity. First, this would be a misconception: given that GDP increases more than employment (due to a simultaneous increase in wages), the employment productivity in monetary terms increases. But beyond that, this is an indicator of how poor a compass neoclassical and neoliberal economic thinking could be for navigating the transition. Providing access to dignified jobs should be one of the main goals of the economy. The disruption brought about by the transition on the jobs of fossil fuel-dependent individuals and communities needs to be directly addressed because of justice considerations and to prevent transition barriers. Addressing this nonequilibrium (also out of the reach of neoclassical general equilibrium economic thinking) disturbance requires a jobs' surplus (higher number of created jobs than lost jobs) to address the many misalignments
} 
distribution of jobs gained and lost may not be in alignment. Similarly, new job creation may not occur within the same time scale as jobs losses, and training misalignments can also be expected, requiring additional adjustment measures. Moreover, other economic sectors than the energy sector can experience transition-related employment impacts, calling for a holistic labour policy that applies just transition considerations across all the economy.

It is against this backdrop-diverging transition outcomes as well as spatial and temporal adjustments needs- that policies for economic restructuring are needed to spread the benefits of the transition widely and to minimize the burdens and costs. Such policies are essential not only as a matter of fundamental fairness but also to limit the likelihood that those negatively impacted will continue to oppose policies required to render the world's economies climate-safe.

A policy vision going beyond the short-sighted paradigm of current competitive advantages is needed to successfully navigate the global transition, addressing the structural inequality issues that prevent certain economies to thrive, and providing the required socio-economic resilience. Current comparative advantages stem from past industrial policy or lack thereof, leading to a very unlevel playing field in today's globalized and highly competitive context [60]. The transition demands higher focus on collaborative contexts.

Strengthening domestic industrial capacities of relevance to a sustainable energy sector needs to be an intrinsic part of the energy transition process. The significant strides made by countries such as Brazil, China and India lend credence to the role of policy-making in fostering such capacities. Practices such as reverse engineering, incremental learning, and prototyping have helped build manufacturing competence [60].

Countries in which domestic markets are too small for a viable localization strategy may succeed through coordinated collaborative efforts with adjacent or like-minded countries, under which each economy can contribute in an innovative way to different segments of the value chain for shared progress. Clear government targets are indispensable for such virtuous outcomes.

\footnotetext{
Footnote 27 (continued)

between the lost and created jobs. Moreover, the 4th industrial revolution (automation, digitalization etc.) that will unfold in parallel with the energy transition will bring about huge decreases of employment intensity in many economic sectors, and thus will require (among other measures) the increase of employment intensity in other economic sectors in order to avoid an increasing unemployment rate. But most of all, when welfare is used as an economic target instead of monetized productivity, increases in dignified job opportunities and improvements in the social value of jobs do contribute to a better performance of the economy and improvements of welfare.
}

The ability to expand renewable energy capabilities in a timely manner and to build underlying industrial capacities hinges to a significant degree on targeted education and skill-training programmes. It also requires careful alignment of educational institutions and programmes while localizing efforts in the renewable energy sector. The lack of such efforts can limit a country's ability to take full advantage of emerging opportunities in the energy transition.

Reinforcing other parts of the economy with high social value and employment intensity (caring economy, social services, education, health...) should also be part of holistic employment policy for the transition.

Since acquiring new skills can be a difficult process, and because of geographical and temporal employment misalignments, it is necessary to establish appropriate social protection measures for affected individuals and communities. This also calls for a more holistic approach to labour policies, expanding them beyond the energy sector to encompass other sectors that can support the socio-economic transition and contribute to improving human welfare, while simultaneously addressing other transition challenges, such as the unemployment trend stemming from higher automation. Governments also may choose to develop public work programmes to bridge the period required for revitalizing local and regional economies and reinforcing post-transition economies.

An important part of the energy transition process relates to notions of what is socially and economically just. Just transition policies must encompass efforts to minimize the adjustment burdens on regions and communities dependent on fossil fuels. Without such initiatives, these regions and communities may not be able to re-orient their economies to take advantage of the emerging opportunities and hence can become barriers for the advancement of the transition.

The types of policies briefly sketched here-integrating measures relating to the energy sector with broader economy considerations, strengthening domestic supply chain capabilities, diversifying economies, reorienting fossil fueldependent regions, shifting towards collaborative contexts, and creating a comprehensive industrial policy framework with strong institutions-allow countries to make the most of the momentous energy transition that is unfolding now and over the next few decades. Taking such measures will contribute to turn the challenges presented by the energy transition into an opportunity for substantial socio-economic gains.

Acknowledgements The macroeconomic modelling associated with this work was carried out with E3ME by Jon Stenning, Hector Pollitt, Eva Alexandri, and other team members of Cambridge Econometrics, UK.

Open Access This article is distributed under the terms of the Creative Commons Attribution 4.0 International License (http://creativeco 
mmons.org/licenses/by/4.0/), which permits unrestricted use, distribution, and reproduction in any medium, provided you give appropriate credit to the original author(s) and the source, provide a link to the Creative Commons license, and indicate if changes were made.

\section{References}

1. Greenpeace: Renovables $100 \%$. http://archivos.greenpeace.org/ espana/es/reports/informes-renovables-100/ (2006). Accessed 9 Aug 2019

2. Greenpeace: Energia 3.0: http://www.revolucionenergetica.es/ ingles/ (2011). Accessed 9 Aug 2019

3. Greenpeace: GWEC, Solar Power Europe. Energy [r]evolution: a sustainable World Energy Outlook. Netherlands (2015)

4. Jacobson, M.Z., et al.: $100 \%$ clean and renewable wind, water, and sunlight all-sector energy roadmaps for 139 countries of the world. Joule 1(1), 108-121 (2017). https://doi.org/10.1016/j.joule .2017 .07 .005

5. Ram, M., Bogdanov, D., Aghahosseini, A., Gulagi, A., Oyewo, A.S., Child, M., Caldera, U., Sadovskaia, K., Farfan, J., Barbosa, LSNS., Fasihi, M., Khalili, S., Dalheimer, B., Gruber, G., Traber, T., De Caluwe, F., Fell, H.-J., Breyer, C.: Global energy system based on $100 \%$ renewable energy - power, heat, transport and desalination sectors. Study by Lappeenranta University of Technology and Energy Watch Group, Lappeenranta, Berlin (2019)

6. Navigant: Energy transition within $1.5^{\circ} \mathrm{C}$ : a disruptive approach to $100 \%$ decarbonisation of the global energy system by 2050 . New York (2018)

7. Teske, S. (ed.): Achieving the Paris climate agreement goals: global and regional $100 \%$ renewable energy scenarios with nonenergy GHG pathways for $+1.5{ }^{\circ} \mathrm{C}$ and $+2{ }^{\circ} \mathrm{C}$. University of Technology Sydney (2019)

8. IEA: World Energy Outlook. Organisation for Economic Cooperation and Development, Paris (2018)

9. IEA: World Energy Model documentation. Organisation for Economic Co-operation and Development, Paris (2018)

10. IEA: World Energy Outlook. Organisation for Economic Cooperation and Development, Paris (1993)

11. IEA: Accelerating global clean energy transitions. Organisation for Economic Co-operation and Development, Berlin energy transition dialogue (2019)

12. IPCC: Fifth Assessment Report, IPCC. Cambridge University Press, Cambridge (2014)

13. van Vuuren, D., Hof, A., Gernaat, D., Sytze de Boer, H.: Limiting global temperature change to $1.5^{\circ} \mathrm{C}$ : implications for carbon budgets, emission pathways, and energy transitions. PBL Netherlands Environmental Assessment Agency, The Hague (2017)

14. Creutzig, F., et al.: The underestimated potential of solar energy to mitigate climate change. Nat. Energy 2(9), 17140 (2017). https://doi.org/10.1038/nenergy.2017.140

15. Carbon Tracker, Grantham Institute: Expect the unexpected: the disruptive power of low-carbon technology, UK (2017)

16. Kriegler, E., Luderer, G., Bauer, N., Baumstark, L., Fujimori, S., Popp, A., Rogelj, J., Strefler, J., van Vuuren, D.P.: Pathways limiting warming to $1.5^{\circ} \mathrm{C}$ : a tale of turning around in no time? Philos. Trans. R. Soc. A 376, 20160457 (2018)

17. IPCC, 2018: Global warming of $1.5^{\circ} \mathrm{C}$. An IPCC special report on the impacts of global warming of $1.5^{\circ} \mathrm{C}$ above pre-industrial levels and related global greenhouse gas emission pathways, in the context of strengthening the global response to the threat of climate change, sustainable development, and efforts to eradicate poverty [Masson-Delmotte, V., Zhai, P., Pörtner, H.-O., Roberts, D., Skea, J., Shukla, P.R., Pirani, A., Moufouma-Okia, W., Péan, C., Pidcock, R., Connors, S., Matthews, J.B.R., Chen,
Y., Zhou, X., Gomis, M.I., Lonnoy, E., Maycock, T., Tignor, M., Waterfield, T. (eds.)] (In Press)

18. Mercure, J.-F., et al.: Modelling complex systems of heterogeneous agents to better design sustainability transitions policy. Glob. Environ. Change 37, 102-115 (2016)

19. Mercure, J.-F., et al.: Environmental impact assessment for climate change policy with the simulation-based integrated assessment model E3ME-FTT-GENIE. Energy Strat. Rev. 20, 195-208 (2018)

20. Knobloch, F., Lam, A., Mercure. J.-F.: Multi-sectoral interactions in low-carbon transitions: simulating the co-evolution of energy production and end-use sectors. In: 9th International Sustainability Transitions Conference, Ottawa (2018)

21. IRENA: Renewable Energy Benefits: Measuring the Economics. International Renewable Energy Agency, Abu Dhabi (2016)

22. OECD/IEA and IRENA 2017: Perspectives for the energy transition: Investment needs for a low carbon energy system. Paris, Abu Dhabi (2017)

23. IRENA: Global Energy Transformation: A View to 2050. International Renewable Energy Agency, Abu Dhabi (2018)

24. IRENA: Global Energy Transformation: A Roadmap to 2050 (2019 Edition). International Renewable Energy Agency, Abu Dhabi (2019)

25. Meadows, D.: Thinking in Systems: A Primer. Earthscan, London (2009)

26. Sovacool, B.K.: Energy studies need social science. Nature 511, 529-530 (2014)

27. Cambridge Econometrics, GHK, IER: Studies on sustainability issues-green jobs; trade and labour. Final Report for the European Commission, DG Employment (2011)

28. Cambridge Econometrics: Preparing for Brexit, London (2018)

29. Synapse Energy Economics: (Mis)understanding climate policy the role of economic modelling, UK (2014)

30. European Commission: IMPACT ASSESSMENT, a policy framework for climate and energy in the period from 2020 up to 2030, $\{\mathrm{COM}(2014) 15$ Final $\}\{\operatorname{SWD}(2014) 16$ Final $\}$, in European Commission Report (2014)

31. Pollitt, H., et al.: An economic and environmental assessment of future electricity generation mixes in Japan - an assessment using the E3MG macro-econometric model. Energy Policy 67, 243-254 (2014)

32. Pollitt, H., et al.: Macroeconomic analysis of the employment impacts of future EU climate policies. Clim. Policy 15(5), 604$625(2015)$

33. Barker, T., et al.: GDP and employment effects of policies to close the 2020 emissions gap. Clim. Policy 16(4), 393-414 (2016)

34. Kober, T., et al.: Macroeconomic impacts of climate change mitigation in Latin America: a cross-model comparison. Energy Econ. 56, 625-636 (2016)

35. European Commission: IMPACT ASSESSMENT, proposal for a directive of the European Parliament and of the Council Amending Directive 2012/27/EU on energy efficiency, \{COM(2016) 761 Final $\}$ SWD(2016) 406 Final $\}$. European Commission Report (2016)

36. Holden, P.B., et al.: Climate—carbon cycle uncertainties and the Paris agreement. Nat. Clim. Change 8, 609-613 (2018)

37. Barker, T., et al.: E3ME Technical Manual: Version 6.0. Cambridge Econometrics, Cambridge (2014)

38. Keen, S.: Debunking Economics: The Naked Emperor Dethroned?. Zed Books Ltd, New York, London (2011)

39. Riahi, K., et al.: The shared socio-economic pathways and their energy, land use, and greenhouse gas emissions implications: an overview. Glob. Environ. Change 42, 153-168 (2017)

40. Samir, K.C., Wolfgang, L.: The human core of the shared socioeconomic pathways: population scenarios by age, sex and level 
of education for all countries to 2100. Glob. Environ. Change 42, 181-192 (2017)

41. Leimbach, M., Kriegler, E., Roming, N., Schwanitz, J.: Future growth patterns of world regions-a GDP scenario approach. Glob. Environ. Change 42, 215-225 (2017)

42. IRENA: Power System Flexibility for the Energy Transition, Part 1: Overview for policy Makers. International Renewable Energy Agency, Abu Dhabi (2018)

43. IRENA: Power System Flexibility for the Energy Transition, Part 2: IRENA FlexTool Methodology. International Renewable Energy Agency, Abu Dhabi (2018)

44. ICF Resources LLC: Economic Analysis of US Decarbonization Pathways: Summary and Findings. ICF Resources LLC, Fairfax (2015)

45. Synapse Energy Economics, Labor Network for Sustainability and 350.org: The clean energy future: protecting the climate, creating jobs and saving money. Synapse Energy Economics, MA (2015)

46. CNREC (China National Renewable Energy Centre): China 2050 high renewable energy penetration scenario and roadmap study. Energy Research Institute, National Development and Reform Commission, Energy Foundation. http://www.cnrec.org.cn/engli sh/result/2015-05-26-474.html (2015). Accessed 12 Aug 2019

47. Blazejczak, J., et al: Economic effects of renewable energy expansion: a model-based analysis for Germany. Discussion Papers, German Institute for Economic Research, DIW Berlin (2011)

48. Lehr, U., Lutz, C., Edler, D.: Green Jobs? Economic impacts of renewable energy in Germany. Energy Policy 47, 358-364 (2012)

49. Callonnec, G., et al.: Mix Électrique 100\% Renouvelable à 2050: Évaluation Macroéconomique-Impacts et Enjeux Économiques de la Transition Énergétique (A 100\% Renewable Mix by 2050: Macro-economic assessment-Economic Impacts and Stakes of the Energy Transition). Agence de l'Environnement et de la Maîtrise de l’Énergie, Paris (2016)
50. Wills, W., Grottera, C.: Economic and social implications: Brazilian GHG mitigation scenarios to 2030. IES-Brasil Project, Rio de Janeiro (2015)

51. Pollin, R., Garrett-Peltier, H., Heintz, J., Scharber, H.: Green recovery. A program to create good jobs and start building a lowcarbon economy. PERI (2008)

52. UNIDO, GGGI: GLOBAL GREEN GROWTH: clean energy industrial investments and expanding job opportunities. Volume II: experiences of Brazil, Germany, Indonesia, the Republic of Korea and South Africa. Vienna and Seoul (2015)

53. GGGI: Annual report 2018. Partnering to catalyze green growth. Seoul, Republic of Korea (2018)

54. OECD (2017): Green Growth Indicators 2017. OECD Green Growth Studies. OECD Publishing, Paris (2018)

55. Ocasio-Cortez, A.: H. Res. 109-116th congress: recognizing the duty of the Federal Government to create a Green New Deal (2019)

56. Klein, N.: On Fire: The (Burning) Case for a Green New Deal. Simon \& Schuster, New York (2019)

57. Jason, Hickel J., Kallis, G.: Is green growth possible? New Political Econ. (2019). https://doi.org/10.1080/13563467.2019.15989 64

58. Bernes, J.: Between the devil and the green new deal. Commune, Issue 3. https://communemag.com/between-the-devil-and-thegreen-new-deal/ (2019). Accessed 12 Aug 2019

59. Riofrancos, T.: Plan, mood, battlefield-reflections on the green new deal. Viewpoint magazine, https://www.viewpointm ag.com/2019/05/16/plan-mood-battlefield-reflections-on-thegreen-new-deal/ (2019). Accessed 12 Aug 2019

60. Chang, H.-J.: Bad Samaritans: The Myth of Free Trade and the Secret History of Capitalism. Bloomsbury Press, London (2008) 